\title{
VERIFICAÇÃO DO NÍVEL DE ATENDIMENTO AOS PROGRAMAS DE AUTOCONTROLE EM INDÚSTRIAS DE LATICÍNIOS DE MINAS GERAIS
}

\author{
Verification of attendance level to self-control programs \\ at industries of Minas Gerais state
}

\begin{abstract}
Hélio dos Santos Benedito Júnior ${ }^{l}$, Vanessa Aglaê Martins Teodoro ${ }^{1,2 *}$, Nívea Maria Vicentini ${ }^{3}$, Márcio Roberto Silva ${ }^{3}$, Renata Golin Bueno Costa ${ }^{4}$, Elisângela Michele Miguel ${ }^{4}$, Denise Sobral ${ }^{4}$, Junio César Jacinto de Paula ${ }^{4}$
\end{abstract}

\section{RESUMO}

Doenças de origem alimentar (DOA) constituem um grave problema de saúde pública em nível mundial. O leite e seus derivados estão frequentemente envolvidos em surtos de DOA. Nos últimos anos, o governo brasileiro tem realizado vários esforços objetivando a prevenção dessas doenças, dentre eles, a aprovação de diversas normas relacionadas à implementação de programas de qualidade em laticínios. Diante deste contexto, este trabalho teve como objetivo avaliar o nível de implementação dos programas de autocontrole (PAC) em indústrias de laticínios. Foram avaliadas 15 indústrias, situadas no sul do estado de Minas Gerais, registradas no Serviço de Inspeção Federal (SIF). Uma lista de verificação (LV) foi desenvolvida e aplicada pelo método da observação direta e por meio de indagações aos funcionários e proprietários. Todos os estabelecimentos avaliados foram classificados como "Ruim" ou "Péssimo", demonstrando que não atendiam nem a $50 \%$ dos itens descritos na legislação para implementação dos PAC. As indústrias também foram avaliadas isoladamente para cada elemento de controle obtendo classificações diversas dentre "Ótimo" (entre 91 a 100\% de adequação),

1 Mestrado Profissional em Ciência e Tecnologia do Leite e Derivados, Universidade Federal de Juiz de Fora, Juiz de Fora, MG, Brasil.

2 Universidade Federal de Juiz de Fora, Departamento de Medicina Veterinária, Rua Espírito Santo, 993, Centro, 36010-041, Juiz de Fora, MG, Brasil. E-mail: vanessa.teodoro@ufjf.edu.br

3 Embrapa Gado de leite, Juiz de Fora, MG, Brasil.

4 Empresa de Pesquisa Agropecuária de Minas Gerais, Instituto de Laticínios Cândido Tostes, Juiz de Fora, MG, Brasil.

* Autor para correspondência. 
"Bom" (70 a 90\%), "Regular" (50 a 69\%), "Ruim" (20 a 49\%) e "Péssimo" (0 a $19 \%$ ). Os resultados demonstraram que as indústrias avaliadas neste trabalho, embora sejam empresas sob inspeção federal, possuem sérias deficiências em seus PAC que podem comprometer a inocuidade dos produtos acabados, visto que não há uma gestão da qualidade eficiente e eficaz.

Palavras-chave: qualidade; inocuidade; leite; lácteos.

\begin{abstract}
Foodborne diseases are the most serious public health issues in the world. Milk and dairy products are often involved in outbreaks of foodborne illnesses. Recently, the Brazilian government has made several efforts to prevent these diseases, among them, approval of several standards related to the adoption of quality programs in dairy products. In this context, this study aimed to evaluate the level of implementation of self-control programs in dairy industries. Fifteen dairy industries settled in South of Minas Gerais state and registered in the Brazilian federal inspection service were evaluated. A checklist was developed and applied by the method of direct observation and also through inquiries to employees and owners. All evaluated establishments were classified as "bad" or "extremely bad", demonstrating that they did not meet even $50 \%$ of items described in the legislation for self-control programs implementation (SCPI). Industries were also evaluated separately for each control element obtaining different rankings from "great" (between 91 and 100\% suitability), "good" (70 to $90 \%$ ), "regular" (50 to 69\%), "bad" (20 to 49\%) and "extremely bad"(00 to 19\%). The results showed that industries evaluated in this study have serious deficiencies in their SCPI, which may compromise the safety of finished products since there is no efficient and effective quality management.
\end{abstract}

Keywords: quality; safety; milk; dairy.

\section{INTRODUÇÃO}

Em todo o mundo as indústrias de alimentos devem implementar programas de qualidade com a finalidade de produzir alimentos inócuos, além de atender a requisitos de identidade e qualidade. Leite e derivados possuem um papel importante na saúde pública, pois são frequentemente manipulados de maneira incorreta, sendo expostos por períodos prolongados a temperaturas inadequadas, além dos frequentes casos de fraudes em toda a cadeia produtiva, dentre outros (TEODORO et al., 2017).

Os laticínios registrados no Serviço de Inspeção Federal (SIF) têm vivenciado nos últimos anos, um avanço e um aprimoramento das normas relacionadas à segurança de alimentos (BRASIL, 1997; 1998; 2003; 2009; 2017b). Essas normas possuem extrema importância para o setor laticinista, pois impactam diretamente nas áreas econômica, financeira e de saúde pública.

Desde 2009, os programas de qualidade exigidos pelo Ministério da Agricultura, Pecuária e Abastecimento (MAPA) foram agrupados em um único programa denominado programa de autocontrole (PAC). Desta forma, as Boas Práticas de Fabricação (BPF), os Procedimentos-padrão de Higiene Operacional (PPHO) e a Análise de Perigos e Pontos Críticos de Controle (APPCC) tiveram sua abordagem revista, sendo complementados e organizados em 
elementos de controle. Assim, os laticínios podem optar por implementar o PAC ou permanecer com seus programas de qualidade, implementados na forma de BPF, PPHO e APPCC, desde que seu o conteúdo contemple todos os elementos de controle descritos na norma do PAC (BRASIL, 2017b).

A implementação desses programas visa o controle da produção desde a obtenção da matéria-prima, durante o processamento, transporte e comercialização, minimizando perdas e garantindo qualidade e segurança. A indústria de laticínios necessita aperfeiçoar o seu sistema de gestão da qualidade de forma a abranger toda a cadeia produtiva. Por outro lado, os órgãos reguladores precisam ser mais ágeis na aprovação de normas que orientem as indústrias (TEODORO et al., 2017).

Algumas ferramentas auxiliam os laticínios no diagnóstico de não conformidades e na verificação dos seus PAC. A análise observacional, por meio da aplicação de uma lista de verificação (LV) ou check-list, tem sido bastante utilizada. A LV permite verificar se os itens exigidos pela legislação estão sendo cumpridos e determinar o grau de adequação do laticínio (SANTOS; HOFFMANN, 2010).

Diante do exposto, este trabalho teve como objetivo verificar o nível de implementação dos PAC em indústrias de laticínios registradas no SIF por meio da aplicação de LV elaborada de forma a contemplar todos os requisitos legais.

\section{MATERIAL E MÉTODOS}

\section{Seleção das Indústrias}

Foram selecionadas 15 indústrias de laticínios inspecionadas pelo SIF, situadas no sul do estado de Minas Gerais, classificadas como fábricas de laticínios ou usinas de beneficiamento, segundo o Regulamento de Inspeção Industrial e Sanitária de Produtos de Origem Animal (RIISPOA) (BRASIL, 2017b). Os estabelecimentos processavam entre 2.000 e 30.000 litros de leite por dia e comercializavam seus produtos em âmbito nacional.

\section{Elaboração da Lista de Verificação (LV)}

Para elaborar a LV que avaliou o percentual de implantação dos PAC foi realizada pesquisa documental em sites eletrônicos para levantamento das legislações vigentes, guias de procedimentos e artigos científicos.

Todas as normas de qualidade vigentes foram utilizadas para complementar os itens de verificação dos elementos de inspeção descritos em Brasil (2009): (PAC1) Manutenção das instalações e equipamentos; (PAC 2) Vestiários, sanitários e barreiras sanitárias; (PAC 3) Iluminação; (PAC 4) Ventilação; (PAC 5) Água de abastecimento; (PAC 6) Águas residuais; (PAC 7) Controle integrado de pragas; (PAC 8) Limpeza e sanitização; (PAC 9) Higiene, hábitos higiênicos, treinamento e saúde dos operários; (PAC 10) Procedimentos sanitários das operações; (PAC 11) Controle de matérias-primas, ingredientes e material de embalagem; (PAC 12) Controle de temperaturas; (PAC 13) Calibração e aferição de instrumentos de controle de processo; (PAC 14) Verificação do programa de APPCC; (PAC 15) Controles laboratoriais e análises; (PAC 16) Controle de formulação dos produtos fabricados. Desta forma, a LV utilizada neste trabalho foi composta por 244 itens de verificação distribuídos entre os 16 elementos de controle que compõem todo o PAC.

Foi utilizado o ofício 07 de 11 de setembro de 2009 (BRASIL, 2009), sem prejuízo do descrito na Norma Interna $n^{\circ} 01$ de 08 de março de 2017 (BRASIL, 2017a), como norma base para orientação dos itens da LV por considerarmos que este é o documento mais completo acerca de requisitos para implementação, monitoramento e verificação dos PAC. 


\section{Aplicação da lista de verificação (LV)}

As informações foram obtidas utilizando-se o método da observação direta e também por meio de indagações aos funcionários e proprietários. As visitas foram realizadas em dias aleatórios, sem aviso prévio, durante o funcionamento das indústrias. $\mathrm{O}$ número de auditorias variou em função da complexidade da indústria, sendo realizadas durante o ano de 2017.

Foram verificados todos itens da lista, respondendo "adequado" (AD) para os requisitos que estavam em conformidade com a legislação ou "inadequado" (IN), para aqueles não conformes. Quando a informação não era aplicada às atividades da empresa, foi considerado "não se aplica" (NA).

$\mathrm{Na}$ sequência, os estabelecimentos e elementos de controle foram pontuados quanto ao nível de adequação, segundo a metodologia descrita na RDC no 275 de 23 de outubro de 2002 da Agência Nacional de Vigilância Sanitária (ANVISA, 2002). Assim, para os itens com resposta SIM, foi atribuído o valor um (1) e para os itens cuja resposta foi NÃO, o valor zero (0). As respostas NA não foram consideradas para contabilização do cálculo de classificação do percentual de atendimento dos elementos de inspeção. As respostas SIM foram somadas e em seguida foi calculada a percentagem de adequação, por meio da Equação 1 (ANVISA, 2002).

$$
\mathrm{PA}=\frac{(\text { itens atendidos })}{(\text { itens julgados })} \times 100
$$

Onde:

PA $=$ Porcentagem de adequação

Itens atendidos $=$ número de respostas SIM (ou AD)

Itens julgados $=$ número total de respostas SIM e NÃO (ou AD + IN)

Considerando os percentuais de aten- dimento encontrados, os estabelecimentos foram classificados em cinco categorias distintas, de acordo com os critérios utilizados por Stangarlin et al. (2013): "Ótimo" (entre 91 a 100\% de adequação), "Bom" (70 a 90\%), "Regular" (50 a 69\%), "Ruim" (20 a 49\%) e "Péssimo" (0 a 19\%).

\section{RESULTADOS E DISCUSSÃO}

É possível observar na Tabela 1 que nenhuma das empresas avaliadas apresentava controle total do processo, visto que o maior nível de adequação com relação à implementação de todo PAC (empresa 1) não chegou à metade do percentual de atendimento à legislação. Todos os estabelecimentos foram classificados como "ruim" (40\%) ou "péssimo" (60\%) no índice geral de adequações. Esses resultados permitem concluir que, embora a primeira norma do MAPA específica de programas de qualidade (BRASIL, 1997) tenha sido publicada há mais de 20 anos, as empresas ainda possuem muita dificuldade em cumprir as exigências legais.

As indústrias avaliadas possuem grande deficiência em demonstrar e documentar adequadamente os itens do PAC relacionados à inocuidade dos produtos, o que revela uma situação bastante preocupante, pois pode influenciar diretamente na qualidade microbiológica dos seus produtos finais (NICOLOSSO, 2010). Pesquisas têm demonstrado que falhas na implementação dos programas de qualidade, como as verificadas no presente trabalho, são as principais responsáveis pela contaminação de produtos lácteos (OKURA; MOACIR, 2010; SILVA et al., 2010).

Verifica-se na Figura 1 que quando avaliada a classificação das indústrias segundo a adequação de cada elemento de controle, percebe-se alto índice de empresas classificadas como "péssimo". A classificação "ótimo" foi observada somente nos PAC 1, 5 e 9 e em $7 \%$ das indústrias analisadas. 
Com relação ao PAC 1 (Manutenção das instalações e equipamentos), a não-conformidade mais recorrente foi a ausência de um programa de manutenção que garantisse uma frequência adequada da manutenção preditiva, preventiva e corretiva. Em $80 \%$ das indústrias havia instalações precárias como pisos quebrados e soltos e não era realizada qualquer manutenção de equipamentos e/ou instalações, o que pode expor o consumidor a perigos físicos como fragmentos e peças de equipamentos (FOOD INGREDIENTS BRASIL, 2008), além de afetar a segurança do trabalhador. Além disso, em $80 \%$ das unidades fabris verificou-se alterações estruturais, sem prévia autorização do SIF, apresentando, em todas as situações, contrafluxos nas áreas produtivas, contrariando o disposto no RIISPOA (BRASIL, 2017b).

Com relação ao PAC 2 (Vestiários, sanitários e barreiras sanitárias), foi verificado que $60 \%$ das indústrias não dispunha de pias sem fechamento manual, de papel toalha, sabonete líquido e sanitizante adequados para higienização das mãos. Todas as empresas apresentaram falhas, seja no fornecimento de equipamentos e utensílios ou treinamento e monitoramento dos manipuladores. Assim, é possível inferir que a higienização das mãos não era realizada de forma adequada nestas fábricas.

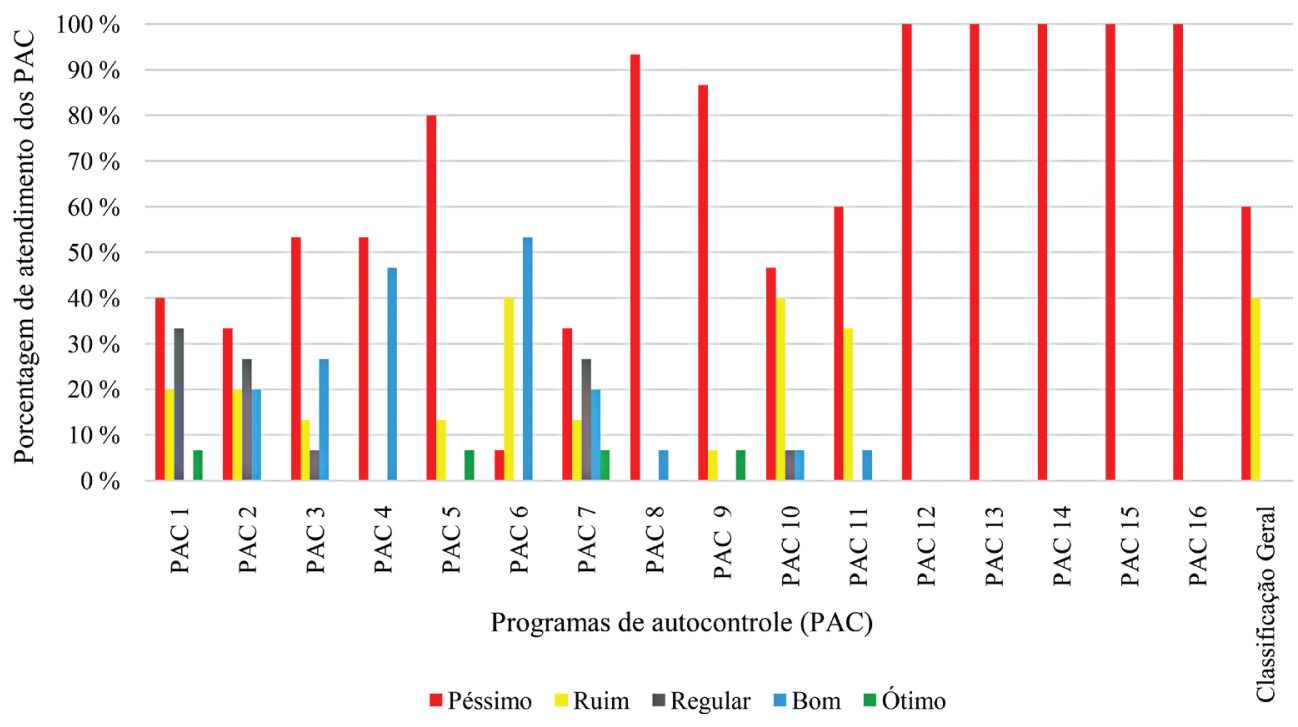

Legenda: Critérios para classificação (\% de atendimento): Ótimo = 91 a $100 \%$; Bom = 70 a $90 \%$; Regular = 50 a $69 \%$; Ruim $=20$ a $49 \%$; Péssimo = 0 a $19 \%$; PAC $1=$ Manutenção das instalações e equipamentos; PAC 2 - Vestiários, sanitários e barreira sanitárias; PAC 3 - Iluminação; PAC 4 - Ventilação; PAC 5 - Água de abastecimentos; PAC 6 - Água residuais; PAC 7 - Controle integrado de pragas; PAC 8 - Limpeza e sanitização; PAC 9 - Higiene, hábitos-higiênicos e saúde dos operários; PAC 10 - Procedimentos Sanitários das Operações; PAC 11 - Controle de matérias-primas, ingredientes e material de embalagem; PAC 12 Controle de temperaturas; PAC 13 - Calibração e aferição dos instrumentos de processo; PAC 14 - Avaliação do programa de Análise de Perigos e Pontos Críticos de Controle; PAC 15 - Controles laboratoriais e análises; PAC 16 - Controle de formulação dos produtos fabricados.

Figura 1 - Porcentagem de empresas classificadas como "ótimo", "bom”, "regular", "ruim" e "péssimo" de acordo com o cumprimento de cada elemento de controle (PAC 1 ao 16) e de todo o programa de autocontrole (classificação geral) 


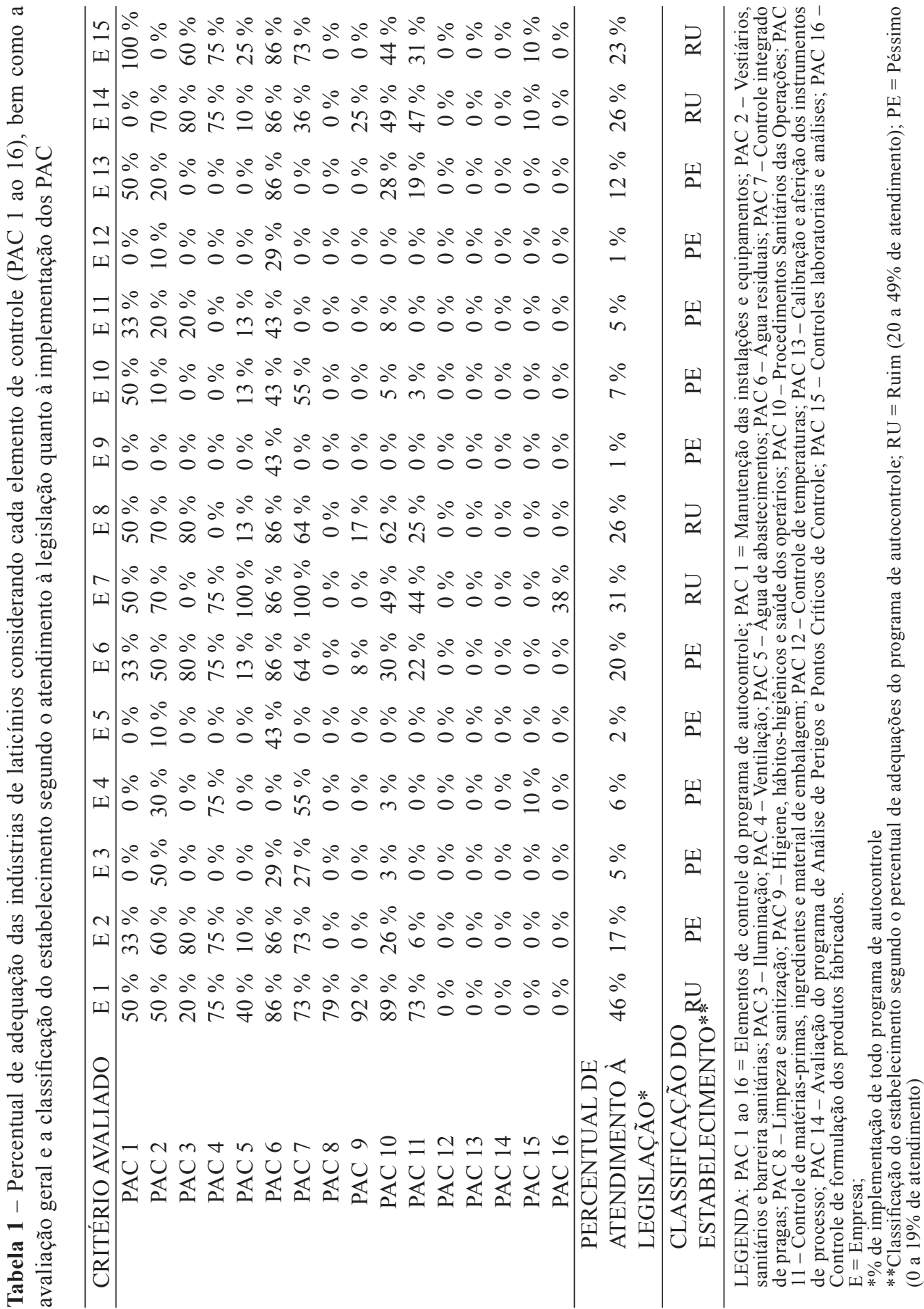


Em $73 \%$ das indústrias faltavam armários para guarda exclusiva de uniformes nos vestiários, sendo que em $86 \%$ os funcionários armazenavam materiais estranhos como dinheiro, alimentos e roupas pessoais junto com os uniformes.

Quando avaliadas as barreiras sanitárias, $20 \%$ não tinha a instalação física. Este fato expõe os produtos durante a sua elaboração a uma série de perigos ou oportunidades de contaminação microbiana, relacionadas a práticas inadequadas de processamento e de manipulação.

Com relação ao PAC 3 (Iluminação), em todas as fábricas inexistia o controle quantitativo da iluminação, sendo constatada baixa luminosidade em áreas de processamento, manipulação, armazenamento e inspeção de matérias-primas e de produtos. Em 100\% dos estabelecimentos foi detectada ausência de proteção em lâmpadas da área de produção, o que representa um risco em caso de queda ou explosão.

A avaliação do PAC 4 (Ventilação) demonstrou total ausência de controle de umidade relativa do ar, o que interfere diretamente na qualidade final, pois permite a variação do teor de umidade de determinados produtos, bem como o desenvolvimento de contaminantes. Além disso, o sistema de ventilação era precário, o que pode prejudicar o controle de odores, de vapores e de condensação, que visa prevenir a alteração dos produtos e o surgimento de condições sanitárias inadequadas no ambiente (BRASIL, 2009; 2017a), além de garantir o conforto térmico dos colaboradores.

Na verificação do PAC 5 (Água de abastecimento), quando considerado o controle da potabilidade da água, $66 \%$ das empresas não tinha qualquer controle ou registro, seja considerando a inspeção do reservatório, a aferição de cloro e pH, a higienização da caixa d'água ou as análises físico-químicas e microbiológicas.

Falhas neste item podem levar à con- taminação da água de abastecimento e, por conseguinte, comprometer a higiene industrial. Chaves et al. (2010), verificou em 10 indústrias de laticínios situados na região de Rio Pomba (MG) que 50\% e $27,78 \%$ das amostras de água apresentaram valores inadequados de coliformes totais e termotolerantes, respectivamente. Os resultados foram relacionados à falta de tratamento da água, à cloração inadequada e à necessidade de assistência técnica e implantação das boas práticas de fabricação.

Quando considerado o PAC 6 (Águas residuais), verificou-se que $66 \%$ dos estabelecimentos apresentou drenagem deficiente, com acúmulo de água no piso de determinados setores produtivos. Além disso, 73\% das indústrias não possuíam ralos sifonados, o que predispõe à presença de odores indesejáveis. Em 53\% dos casos, havia infiltração de água residual nos pisos demonstrando ausência de impermeabilização adequada, condizente com o verificado no PAC 1.

Com relação ao PAC 7 (Controle integrado de pragas), podemos observar que em 33\% dos estabelecimentos, não havia nenhum tipo de controle, seja realizado pela própria empresa ou por terceiros. Foi possível constatar ausência de armadilhas, além da presença de acúmulo de água, abrigos, focos de reprodução de insetos, janelas e portas sem proteção. $\mathrm{O}$ inadequado controle integrado de pragas representa um risco higiênico-sanitário e de prejuízos financeiros, uma vez que pode acarretar perdas de alimentos e matérias-primas, além de danos à saúde pública (BRASIL, 1998).

Avaliando o PAC 8 (Limpeza e sanitização), em 100\% dos estabelecimentos, foi evidenciado o desconhecimento dos manipuladores quanto a conceitos importantes como técnicas de monitorização, verificação, procedimento pré-operacional e operacional, bem como limpeza e sanitização (BRASIL, 2003; 2017a; 2017b).

Nenhuma das empresas apresentou 
programa escrito de limpeza e sanitização, abordando procedimentos para higienização de equipamentos e instalações. Também não havia funcionário responsável pela implementação e monitoramento dos procedimentos executados nos estabelecimentos. Nenhuma indústria apresentou registros completos e frequentes, assinados e datados, documentando a execução dos procedimentos.

Quando considerado o armazenamento e a identificação dos detergentes e sanitizantes, $60 \%$ dos estabelecimentos descumpriu a legislação (BRASIL, 1997), pois não possuía almoxarifado exclusivo para produtos químicos, armazenando estes produtos junto com matérias-primas e insumos sem identificação.

Verificou-se a utilização de utensílios e materiais impróprios para limpeza (tipo, formato, material de constituição, escovas e vassouras que soltavam fragmentos) em $40 \%$ das indústrias. Apenas $20 \%$ das empresas havia treinado os funcionários responsáveis pelo preparo e uso de detergentes e sanitizantes. Nenhum dos estabelecimentos apresentou instalação adequada para higienização eficaz dos veículos.

As falhas apresentadas neste PAC de limpeza e sanitização podem impactar diretamente na qualidade e na incocuidade do produto (CULLER; CONKLIN, 2015). Observa-se que as empresas avaliadas não são capazes de garantir a segurança e a qualidade dos seus produtos sob os aspectos físicos, químicos e microbiológicos. Assim, verificase a necessidade urgente da adequação dos estabelecimentos quanto à implementação do PAC 8 para reduzir a possibilidade de quaisquer danos à saúde do consumidor.

A avaliação do PAC 9 (Higiene, hábitos higiênicos e saúde dos operários) permitiu observar que apenas $20 \%$ das indústrias apresentaram este elemento de controle escrito e implantado. Em todos os estabelecimentos foram evidenciadas práticas anti-higiênicas relacionadas à manipulação dos produtos em processamento ou matéria-prima. Verificaram- se colaboradores trabalhando em áreas suja e limpa sem realizar a higienização adequada e a troca dos uniformes. Além disso, em 100\% das indústrias os manipuladores não possuíam hábitos higiênicos corretos, como a limpeza e assepsia das mãos e antebraços. Essas práticas predispõem à contaminação cruzada dos produtos e devem ser combatidas por meio de treinamentos periódicos e monitorização (BRASIL, 2009).

Em $60 \%$ das indústrias foram identificados controles de troca dos uniformes pelo sistema de numeração ou cores. Apesar disso, apenas 20\% realizava a troca mínima diária e a limpeza irrepreensível desses itens. Em nenhuma das empresas existia procedimento descrito de higienização, bem como higienização realizada pela indústria ou lavanderia terceirizada, conforme determina o RIISPOA (BRASIL, 2017b). Além disso, foram observados hábitos anti-higiênicos de colaboradores uniformizados como o uso de cigarro e a circulação fora da área de produção, como a ida e a volta ao trabalho.

O controle de saúde dos manipuladores era realizado em $60 \%$ dos estabelecimentos, porém, apenas $20 \%$ possuía procedimentos descritos de monitoramento. Este controle é imprescindível nas indústrias de laticínios, uma vez que doenças infecciosas, lesões abertas ou purulentas, portadores assintomáticos de agentes causadores de toxinfecções ou outra fonte de contaminação, podem representar risco à inocuidade do produto. Os colaboradores nestas condições devem ser afastados de suas funções enquanto persistirem os riscos (BRASIL 1998; 2009; 2017b).

Nenhuma das indústrias apresentou plano descrito para treinamento dos funcionários. Também não foi evidenciado treinamento dos manipuladores na ocasião de sua admissão, bem como no decorrer de suas atividades na empresa. Nos casos em que havia monitores e verificadores de autocontroles foi verificado que a maioria 
não demonstrava capacitação para exercer a função.

Com relação ao PAC 10 (Procedimentos Sanitários das Operações), nenhum estabelecimento foi classificado como "ótimo", pois não possuía este elemento de controle totalmente descrito e implementado. Somente $40 \%$ das empresas possuiam instalações com dimensões compatíveis com o processamento, manipulação e armazenamento dos produtos. Em apenas 20\%, evidenciou-se que os equipamentos e instalações foram projetados visando a facilidade de limpeza, de forma a assegurar que não haveria alteração do produto durante o processamento, a manipulação e a estocagem.

Em $40 \%$ das indústrias foram encontrados utensílios de madeira, com resíduos de alimentos e sinais de contaminação. A legislação proíbe o uso de madeira, determinando que os materiais que entram em contato com os produtos devem ser lisos, de fácil higienização, sem fissuras ou ranhuras (BRASIL, 1997). Além disso, a presença de resíduos predispõe à adesão de microrganismos e à formação de biofilmes, comprometendo a qualidade e a inocuidade dos produtos (CLETO et al., 2012).

Nenhum estabelecimento possuía separação entre os utensílios e equipamentos utilizados nas áreas limpas e sujas. Da mesma forma, também não havia identificação e diferenciação dos utensílios para armazenagem de ingredientes e de produtos não comestíveis, conforme determina o RIISPOA (BRASIL, 2017b).

Todas as empresas avaliadas manipulavam leite cru dentro da área produtiva, possibilitando a contaminação cruzada. Procedimentos como estes podem acarretar em contaminação por microrganismos patogênicos, representado um risco para a inocuidade do produto (VERRAES et al., 2015).

Em $100 \%$ das indústrias de laticínios, não existia controle sobre a toxicidade e o grau alimentício de graxas, lubrificantes, etc.
Esta situação demonstra risco de utilização de produtos tóxicos, que podem transferir odor ou sabor estranho aos produtos (BRASIL, 1998; 2009; 2017a).

Em $80 \%$ dos estabelecimentos não existia filtro para o vapor sanitário. Além de descumprir a legislação (BRASIL, 2009; $2017 \mathrm{a}$; 2017b), o vapor pode representar um perigo físico e químico. Recomenda-se, no mínimo, o uso de vapor com qualidade culinária, ou seja, com 95\% de pureza (3-A SANITARY STANDARDS, INC., 2004).

Foi verificada a utilização de insumos e produtos vencidos em $80 \%$ das indústrias de laticínios. A vida de prateleira de alimentos e insumos baseia-se no tempo em que o produto pode ser armazenado sem alterações físico-química, microbiológicas e sensoriais, desempenhando sua função com eficácia (FOOD INGREDIENTS BRASIL, 2008). Assim, neste cenário, o consumidor pode estar exposto a riscos, pois, uma vez que houve falha nos controles dos aditivos e ingredientes, não há garantia do seu desempenho seguro e eficaz.

No PAC 11 (Controle de matérias-primas, ingredientes e material de embalagem) verificou-se que não havia controle da qualidade dos ingredientes e insumos utilizados na fabricação. As empresas devem exigir dos fornecedores documentos que informem sobre sua origem, composição, qualidade e controles (BRASIL, 2009; 2017a).

Foram observadas, em 100\% dos estabelecimentos, falhas na estocagem de matérias-primas e produtos acabados como embalagens não íntegras, ausência de identificação e temperatura inadequada. Este fato predispõe à contaminação e à deterioração dos produtos, prejudicando sua qualidade e segurança e reduzindo sua vida de prateleira, além de impossibilitar a rastreabilidade e o controle adequado do estoque (BRASIL, 2009; DOYLE et al., 1997; CULLER; CONKLIN, 2015).

Nenhum dos estabelecimentos realizava 
todas as análises contempladas na legislação para leite cru (BRASIL, 2011), em vigor no ano de 2017, época da realização do trabalho, sendo a maioria das falhas relacionadas à ausência de testes de reconstituintes e antibióticos. Em 40\% das empresas não havia equipamentos e vidrarias básicas para análises físico-químicas da matéria-prima.

Nenhuma das indústrias armazenava o leite cru na temperatura adequada, quando considerado o limite máximo de $4{ }^{\circ} \mathrm{C}$ (BRASIL, 2017 b), o que possibilita o desenvolvimento de deterioradores e patogênicos.

Dentre as 14 empresas que recebiam leite de produtor, nenhuma possuía programa de educação continuada. Dos estabelecimentos que recebiam a matéria-prima de outro laticínio, em nenhum deles o caminhão apresentava-se devidamente lacrado.

Quando considerada a Instrução Normativa $\mathrm{n}^{\circ}$. 49 de 14 de setembro de $2006,80 \%$ dos estabelecimentos não realizava o controle e a aprovação de produtos de higienização, embalagem, ingredientes e demais insumos, seguindo as instruções para permitir a entrada e o uso de produtos na indústria (BRASIL, 2006).

Em 30\% das empresas foi possível verificar problemas de armazenamento, como ingredientes armazenados junto com produtos de limpeza e com equipamentos de proteção individual (EPI). Este procedimento contraria o disposto no RIISPOA (BRASIL, 2017b) e possibilita a contaminação cruzada dos produtos.

Auditando os requisitos que compõem o PAC 12 (Controle de temperaturas), foi possível verificar que $100 \%$ dos estabelecimentos foram classificados como "péssimo". Estes resultados demonstram um cenário preocupante, uma vez que a temperatura é sempre considerada um ponto de controle (PC) ou um ponto crítico de controle (PCC) (BRASIL, 2009; 2017a) que interfere na qualidade do produto final.
A ausência do registro de temperatura trata-se de uma situação que pode expor os consumidores a riscos. O controle realizado na frequência adequada permite identificar possíveis desvios e aplicar as ações corretivas previstas, bem como demonstrar tendências de variações que permitam a adoção de medidas de controle que evitem a multiplicação de patógenos (BRASIL, 2009; 2017a).

A preocupação é ainda maior quando associamos esta não implantação do PAC 12 (Controle de temperaturas), com os resultados obtidos nos PAC 8 (Limpeza e Sanitização), PAC 9 (Higiene, hábitos higiênicos e saúde dos operários) e PAC 10 (Procedimentos sanitários das operações), que demonstram falhas graves nos controles higiênico-sanitários. Estas falhas aumentam a probabilidade de altas contagens microbiológicas nos produtos em elaboração, além da presença de patógenos.

Vale ressaltar que, dentre as 15 indústrias avaliadas, 3 elaboravam exclusivamente produtos com processamento hermético e envase a quente (doces de leite, sobremesas lácteas, leite condensado, etc.). Das 12 empresas que produziam produtos de alta umidade (queijos frescos e bebidas lácteas) nenhuma pasteurizava o leite, visto que não obedeciam o binômio tempo/temperatura de $72^{\circ} \mathrm{C} / 75^{\circ} \mathrm{C}$ por $15 \mathrm{~s} \mathrm{a} 20 \mathrm{~s}$ (BRASIL, 2017b). Este fato é considerado muito grave, pois o tratamento térmico do leite é imprescindível pra garantir a eliminação de patógenos como Escherichia coli, Sthaphylococcus aureus, Salmonella, Campylobacter, Coxiella burnetii, e Listeria monocytogenes, dentre outros, passíveis de causar doenças nos consumidores (HOLSINGER et al., 1997).

Avaliando os resultados obtidos para o PAC 13 (Calibração e aferição dos instrumentos de processo), observa-se que todas as empresas descumpriram integralmente este elemento de controle. A indústria deve conter equipamentos e instrumentos 
de controle de processos calibrados e aferidos, imprescindíveis para o adequado controle técnico e sanitário da produção (BRASIL,2009; 2017a).

Verifica-se que os resultados das me dições realizadas por estes estabelecimentos são incertos. Tais controles incluem, por exemplo, a aferição de temperaturas durante a higienização, no recebimento e na estocagem de matérias-primas e de produtos, a pesagem de ingredientes, dentre outros. É importante ressaltar que a ausência de calibração interfere diretamente na eficácia e na eficiência do programa APPCC, uma vez que não é possível medir com precisão itens definidos como limites críticos, como, por exemplo, o binômio tempo/temperatura da pasteurização (CULLER; CONKLIN, 2015).

Analisando os resultados obtidos para o PAC 14 (Avaliação do APPCC), $100 \%$ dos estabelecimentos detinham falhas graves nos programas de pré-requisitos, BPF e PPHO, sendo inviável a implementação do APPCC (BRASIL, 1998). Assim, considerando que o APPCC é um sistema preventivo que busca a produção de alimentos seguros (BRASIL, 1998), é possível concluir que as empresas não detêm controle de processo, portanto, não podem garantir a segurança dos seus produtos.

Avaliando os resultados obtidos para o PAC 15 (Controles laboratoriais e análises), constatou-se que todas as empresas estavam utilizando metodologias de análises não reconhecidas, além de apresentarem analistas com conduta inadequada e sem treinamento.

Nenhuma indústria possuía plano de amostragem, nem programa de Boas Práticas de Laboratório (BPL) contemplando manual de bancada, conduta pessoal dentro do laboratório, manipulação e descarte de reagentes e amostras, aferição e calibração de instrumentos, padronização, identificação e armazenagem adequada de reagente, registros de resultados de análises e treinamento dos analistas.
Este resultado indica que, além da ausência do controle de processo, também não havia controle dos produtos acabados, sendo liberados sem avaliação prévia quanto ao atendimento à legislação em termos de padrões microbiológicos e físico-químicos.

Quando observado o PAC 16 (Controle de formulação dos produtos fabricados), foi possível verificar que todas as indústrias elaboravam produtos com formulação diferente do memorial descritivo aprovado pelo SIF, além de não possuírem controles de formulação. Não eram previstas medidas preventivas e corretivas para casos de erros de fabricação ou formulação e, nestes casos, o destino adequado dos produtos. Em 60\% das empresas foi confirmada a utilização de aditivos alimentares acima dos limites recomendados pelo regulamento técnico de identidade e qualidade do produto.

Este elemento de controle é importantíssimo quando considerada a rastreabilidade e as ações de recolhimento (recall) que porventura sejam necessárias, e estejam vinculadas com a utilização de matériasprimas e aditivos impróprios ao consumo humano (ANVISA, 2015).

\section{CONCLUSÕES}

Embora as indústrias avaliadas sejam registradas no SIF e a implementação de programas de qualidade seja uma exigência legal que vigora há mais de 20 anos no País, a classificação das empresas em "péssimo" e "ruim" segundo o grau de adequação à legislação, aponta para a existência de sérias deficiências na implementação destes programas. Isso reforça a necessidade de um maior empenho não só das indústrias em atender aos requisitos legais e garantir os direitos dos consumidores, como também, dos órgãos de inspeção em serem mais rigorosos e fazerem cumprir a legislação. 


\section{REFERÊNCIAS}

3-A SANITARY STANDARDS, INC. 3-A Accepted practices for a method of producing culinary steam (Number 609-03). McLean, VA, 21 nov. 2004.

AGÊNCIA NACIONAL DE VIGILÂNCIA SANITÁRIA (ANVISA). Resolução RDC no 275, de 21 de outubro de 2002. Dispõe sobre o Regulamento Técnico de Procedimentos Operacionais Padronizados aplicados aos Estabelecimentos Produtores/ Industrializadores de Alimentos e a Lista de Verificação das Boas Práticas de Fabricação em Estabelecimentos Produtores/Industrializadores de Alimentos. Diário Oficial da União: seção 1, Brasília, DF, 6 nov. 2002.

AGÊNCIA NACIONAL DE VIGILÂNCIA SANITÁRIA (ANVISA). Resolução RDC n ${ }^{\circ}$ 24 , de 08 de junho de 2015. Dispõe sobre o recolhimento de alimentos e sua comunicação à Anvisa e aos consumidores. Diário Oficial da União: seção 1, Brasília, DF, 9 jun. 2015.

BRASIL. Ministério da Agricultura e Abastecimento. Portaria n ${ }^{\circ} 368$, de 04 de setembro de 1997. Regulamento Técnico sobre as condições Higiênico-Sanitárias e de Boas Práticas de Fabricação para Estabelecimentos Elaboradores/Industrializadores de Alimentos. Diário Oficial da União: seção 1, Brasília, DF, 8 set. 1997.

BRASIL. Ministério da Agricultura e Abastecimento. Portaria $n^{\circ} 46$, de 10 de fevereiro de 1998. Institui o sistema de análise de perigos e pontos críticos de controle: APPCC a ser implantado nas indústrias de produtos de origem animal. Diário Oficial da União: seção 1, Brasília, DF, p. 24, 16 mar. 1998.

BRASIL. Ministério da Agricultura Pecuária e Abastecimento. Resolução $n^{\circ} 10$, de 22 de maio de 2003: Institui o Programa Genérico de PROCEDIMENTOS - PADRÃO DE HIGIENE OPERACIONAL - PPHO, a ser utilizado nos estabelecimentos de Leite e Derivados que funcionam sob o regime de Inspeção Federal, como etapa preliminar e essencial dos Programas de Segurança Alimentar do tipo APPCC (Análise de Perigos e Pontos Críticos de Controle). Diário Oficial da União: seção 1, Brasília, DF, p. 4, 28 maio 2003.

BRASIL. Ministério da Agricultura Pecuária e Abastecimento. Instrução Normativa $n^{\circ}$ 49 de 14 de setembro de 2006. Aprova as Instruções para permitir a entrada e o uso de produtos nos estabelecimentos registrados ou relacionados no Departamento de Inspeção de Produtos de Origem Animal, do Ministério da Agricultura, Pecuária e Abastecimento. Diário Oficial da União: seção 1, Brasília, DF, 20 set. 2006.

BRASIL. Ministério da Agricultura Pecuária e Abastecimento. Ofício Circular $n^{\circ} 07$ DILEI/CGI/DIPOA. Procedimentos de Verificação dos Programas de Autocontrole em estabelecimentos processadores de leite e derivados, mel e produtos apícolas. Diário Oficial da União: seção 1, Brasília, DF, 11 set. 2009.

BRASIL. Ministério da Agricultura Pecuária e Abastecimento. Departamento de Inspeção de Produtos de Origem Animal. Instrução Normativa $n^{\circ}$ 62, de 29 de dezembro de 2011. Regulamento Técnico de Produção, Identidade e Qualidade do Leite tipo A, o Regulamento Técnico de Identidade e Qualidade de Leite Cru Refrigerado, o Regulamento Técnico de Identidade e Qualidade de Leite Pasteurizado e o Regulamento Técnico da Coleta de Leite Cru Refrigerado e seu Transporte a Granel. Diário Oficial da União: seção 1, Brasília, DF, p. 6, 30 dez. 2011. 
BRASIL. Ministério da Agricultura Pecuária e Abastecimento. Norma Interna DIPOA/ SDA $n^{\circ} 01$, de 08 de março de 2017. Aprova os modelos de formulários, estabelece as frequências e as amostragens mínimas a serem utilizadas na inspeção e fiscalização, para verificação oficial dos autocontroles implantados pelos estabelecimentos de produtos de origem animal registrados (SIF) ou relacionados (ER) junto ao DIPOA/SDA, bem como o manual de procedimentos. Diário Oficial da União: seção 1, Brasília, DF, 21 jun. 2017 (a).

BRASIL. Ministério da Agricultura Pecuária e Abastecimento. Departamento de Inspeção de Produtos de Origem Animal. Decreto $n^{\circ}$ 9.013, de 29 de março de 2017. Regulamento de Inspeção Industrial e Sanitária de Produtos de Origem Animal - RIISPOA. Diário Oficial da União: seção 1, Brasília, DF, p. 3, 30 mar. 2017(b).

CHAVES, K. F. et al. Avaliação microbiológica da água empregada em laticínios da região de Rio Pomba-MG. UNOPAR Científica Ciências Biológicas e da Saúde, v. 12, n. 4, p. 5-8, 2010.

CLETO, S. et al. Characterization of contaminants from a sanitized milk processing plant. PLOS ONE, v. 7, n. 6, e 40189, 2012.

CULLER, R; CONKLIN, T. Food safety systems: prerequisite programs and validation. Center Food Ag Bio Michigan State University, mar. 2015. Disponível em: $<$ https://www.canr.msu.edu/productcenter/ uploads/files/Food_Safety_Systems_-_ Prerequisite_Programs_and_Validation.pdf $>$. Acesso em: 15 out. 2017.

DOYLE, M. P.; BEUCHAT, L. R.; MONTVILLE, T. J. Food microbiology: fundamentals and frontiers. Washington: ASM Press, 1997. 768 p.
FOOD INGREDIENTS BRASIL. Segurança Alimentar. Revista Food Ingredients Brasil, n. 4, p. 32-43, 2008.

HOLSINGER, V. H; RAJKOWSKI, K. T; STABEL, J. R. Milk pasteurization and safety: a brief history and update. Scientific and Technical Review of the Office International des Epizooties, v. 16, n. 2, p. 441-451, 1997.

NICOLOSSO, T. F. Proposta de integração entre BPF, APPCC, PAS 220:1997 e a NBR ISO 22000:2006 para indústria de alimentos. 2010. 68 p. Dissertação (Mestrado em Engenharia da Produção) - Universidade Federal de Santa Maria, Santa Maria, 2010.

OKURA, M. H.; MOACIR, J. Avaliação das condições higiênico-sanitárias de queijos minas frescal produzidos com leite cru, leite pasteurizado e de queijo temperado em alguns municípios da região do triângulo mineiro. Revista do Instituto de Laticínios Cândido Tostes, v. 65, n. 375, p. 33-42, 2010.

SANTOS, V. A. Q.; HOFFMANN, F. L. Avaliação das boas práticas de fabricação em linha de processamento de queijos Minas frescal e ricota. Revista do Instituto Adolfo Lutz, v. 67, n. 2, p. 222-228, 2010.

SILVA, R. et al. Pasteurized milk: efficiency of pasteurization and its microbiological conditions in Brazil. Foodborne Pathogens and Disease, v. 7, n. 2, p. 217-219, 2010.

STANGARLIN, L. et al. Instrumentos de apoio para implantação das boas práticas em serviços de nutrição e dietética hospitalar. Rio de Janeiro: Rubio, 2013.

TEODORO, V. A. M. et al. Implementação de programas de autocontrole na indústria de laticínios. Informe Agropecuário. v. 38, n. 299, p. 20-17, 2017. 